\title{
Reduction of Staphylococcus epidermidis adhesion to indwelling medical devices: a simple procedure
}

\author{
C. Sousa, M. Henriques, P. Teixeira and R. Oliveira \\ Institute for Biotechnology and Bioengineering, Centre of Biological Engineering, \\ University of Minho, Campus de Gualtar, 4710-057 Braga, Portugal
}

Accepted: 12 August 2008

\section{Introduction}

Staphylococcus epidermidis is a coagulase-negative staphylococcus (CNS) that often colonises the skin and mucous membranes as an important part of its normal microflora. However, these staphylococci have emerged as the most frequently isolated pathogen in nosocomial sepsis. They are currently responsible for a larger number of indwelling medical device-associated infections than any other group of microorganisms, mainly due to their ability to adhere to biomaterial surfaces and to form biofilms.

Central venous catheter (CVC) infections, for example are a noteworthy cause of morbidity and mortality and a main source of bacteraemia in hospitalised patients. ${ }^{2}$ Infections caused by $S$. epidermidis are generally associated with immunocompromised, long-term hospitalised and seriously ill patients who represent very susceptible hosts. ${ }^{3}$ Initial adhesion of bacteria to the biomaterial surface is thought to be a key step in the colonisation of indwelling medical devices, and therefore ways to reduce it have been studied thoroughly over the past decades.

Owing to the increased resistance of microorganisms to antibiotics, and to host defence mechanisms, it is important to find alternatives to the use of antibiotics. Also, it is crucial to proceed with practices that minimise the risk of the emergence of multiresistant bacteria and reduce transmission of any microorganisms between patients. ${ }^{4}$

Significant attention has been given to the development of materials that inhibit bacterial adhesion and surface colonisation. ${ }^{5}$ Furthermore, the impregnation of biomedical devices with antiseptics has proved to be effective in reducing microbial surface adhesion, thus lowering the risk to patients of nosocomial infection. ${ }^{6}$ Moreover, the binding of specific natural substances (e.g., heparin) to the material surface has been one of the strategies attempted on order to reduce the extent of bacterial adhesion. ${ }^{7-9}$

Heparin is a proteoglycan that has strong anticoagulant activity, ${ }_{10}^{10}$ which is normally used to minimise thrombus formation $^{11}$ and extent the duration of catheter use. ${ }^{12}$ Its strong hydrophilic nature prevents adhesion of bacterial cells, which may constitute a prime quality for an effective anti-adhesive coater. ${ }^{13}$ Nomura et al. ${ }^{14}$ compared the extent of

\section{ABSTRACT}

The present study aims to find a method to reduce Staphylococcus epidermidis adhesion to acrylic and silicone two materials used commonly in medical devices, by heparin and gentian violet surface preconditioning. Different periods of heparin preconditioning are studied to evaluate the influence of preincubation time on the reduction of bacterial adhesion. A two-hour period was chosen and applied in the adhesion assays with either heparin or gentian violet. Squares of the materials with adhered cells were also analysed by scanning electron microscopy (SEM). Results of adhesion assays showed a significant reduction $(53-90 \%, P<0.05)$ in bacterial adhesion to silicone and acrylic after precontact with the conditioning substances. No statistical differences $(P>0.05)$ were found between the extent of adhesion on silicone coupons pre-contacted either with heparin or gentian violet for each of the strains tested. On acrylic, heparin was more efficient $(P<0.001)$ in reducing $S$. epidermidis IE186 adhesion than was gentian violet $(85 \%$ and $53 \%$ reductions, respectively). Therefore, immersion of acrylic and silicone in heparin or gentian violet may constitute a simple and effective method by which to reduce S. epidermidis adhesion to medical devices.

KEY WORDS: Cross infection.

Gentian violet.

Heparin.

Staphylococcus epidermidis.

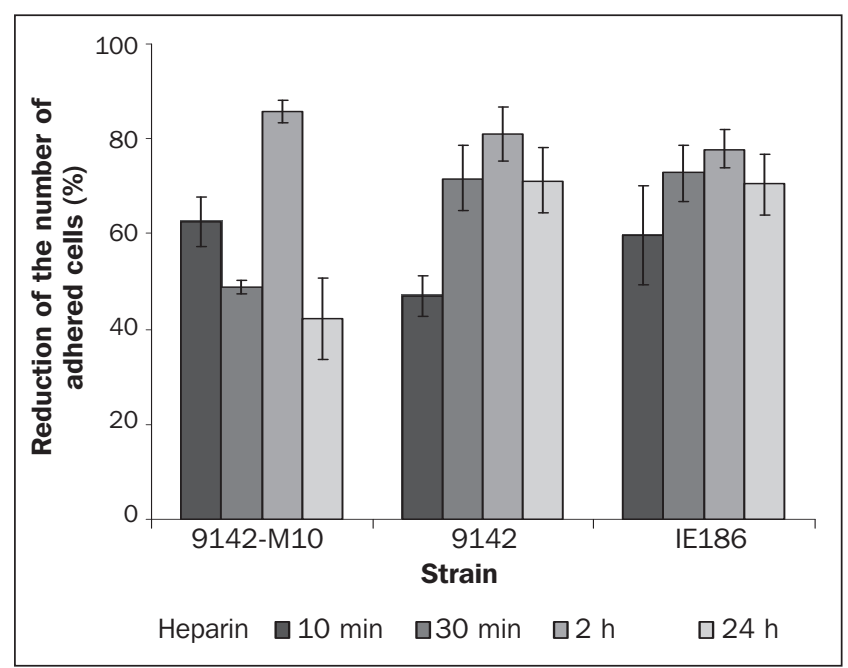

Fig. 1. Number of S. epidermidis cells adherent to control silicone coupons and to silicone coupons subjected to different heparin precontact times (10 $\mathrm{min}, 30 \mathrm{~min}, 2 \mathrm{~h}$ and $24 \mathrm{~h}$ ) for the three strains assayed (9142-M10, 9142 and IE186). Results represent means plus standard deviations (error bars) from three independent experiments. 
S. epidermidis adhesion between heparinised and nonheparinised PVC and silicone and the results showed reduced bacterial adhesion to heparinised surfaces.

Gentian violet $(\mathrm{GV})$ is a triphenylmethane dye normally used to colour wood, silk or paper, and is also applied as a biological stain and antimicrobial agent. ${ }^{15}$ Gentian violet shows good bactericidal activity against some Gram-positive cocci (e.g., Staphylococcus species) and pathogenic yeasts such as Candida spp. ${ }^{16}$ It has been used topically to treat skin lesions $^{17}$ and infections such as thrush in children and oropharyngeal candidiasis. ${ }^{18}$

The aim of the present study is to evaluate the ability of preconditioning of surfaces by heparin or GV to hamper $S$. epidermidis adherence, the ultimate goal being to find a simple method to minimise $S$. epidermidis adhesion and colonisation of indwelling medical devices, and thus reduce associated infections.

\section{Material and methods}

\section{Bacterial strains}

Three strains of S. epidermidis were used. S. epidermidis 9142 is a clinical isolate and known surface polysaccharide intercellular adhesin (PIA)-producer identified as responsible for biofilm formation. ${ }^{19}$ Strain 9142-M10 is an isogenic mutant with a transposon inserted in the ica locus that encodes the proteins involved in PIA production and

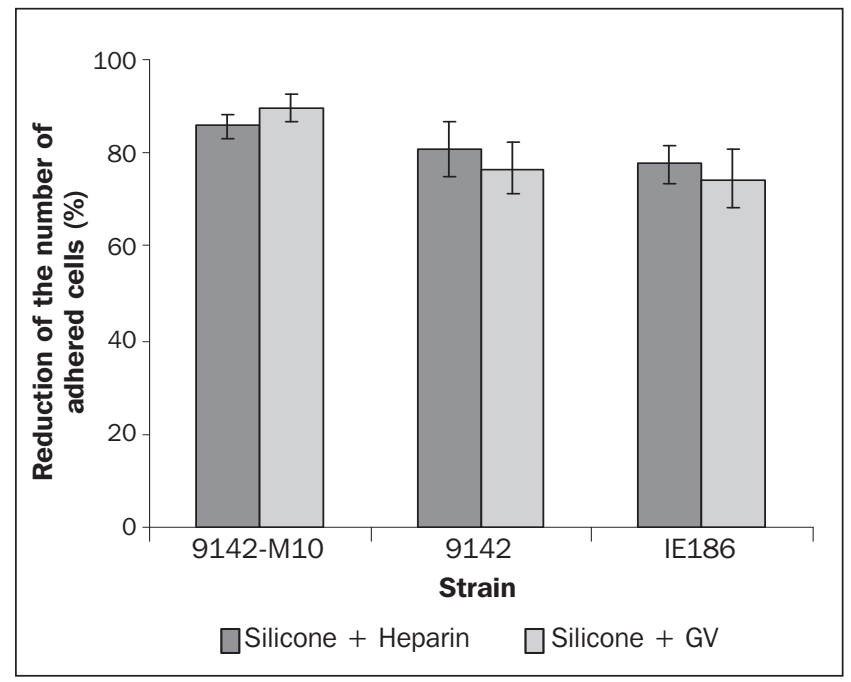

Fig. 2. Effect of heparin and gentian violet precontact on S. epidermidis adhesion to silicone. a) Number of $\mathrm{S}$. epidermidis adhered cells to non-conditioned silicone coupons (control) and to silicone coupons precontacted with heparin or gentian violet (GV), for the three strains assayed (9142-M10, 9142 and IE186). Results represent means plus standard deviations (error bars). b) Representative scanning electron micrographs of the extent of adhesion of the three S. epidermidis strains studied to silicone precontacted with heparin or gentian violet (original magnification $\times 3000$ ).
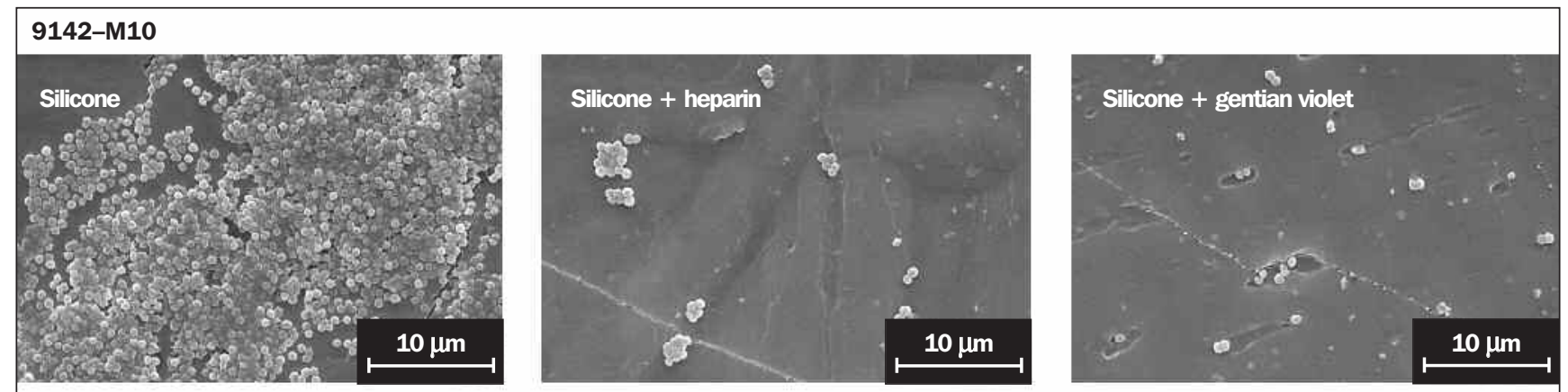

\section{2}
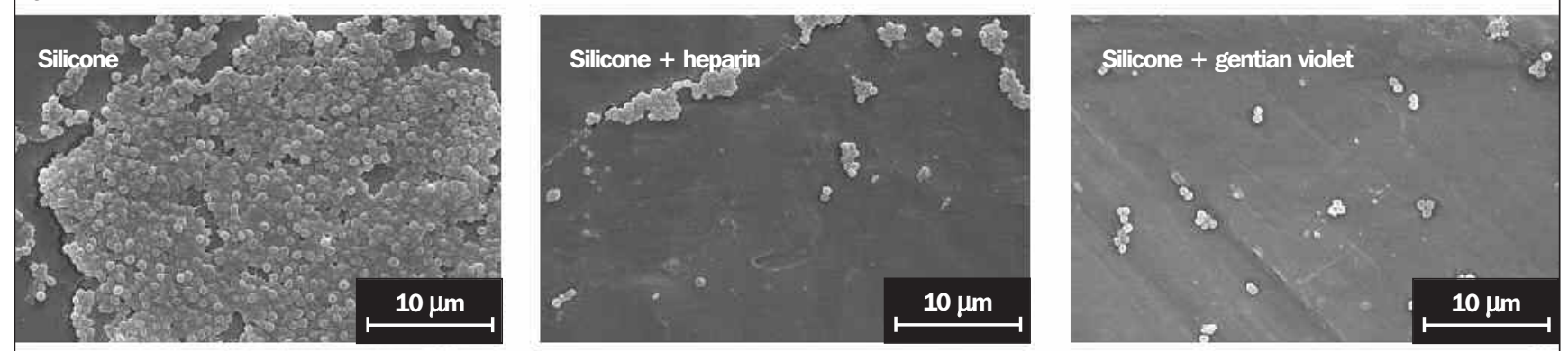

\section{IE 186}
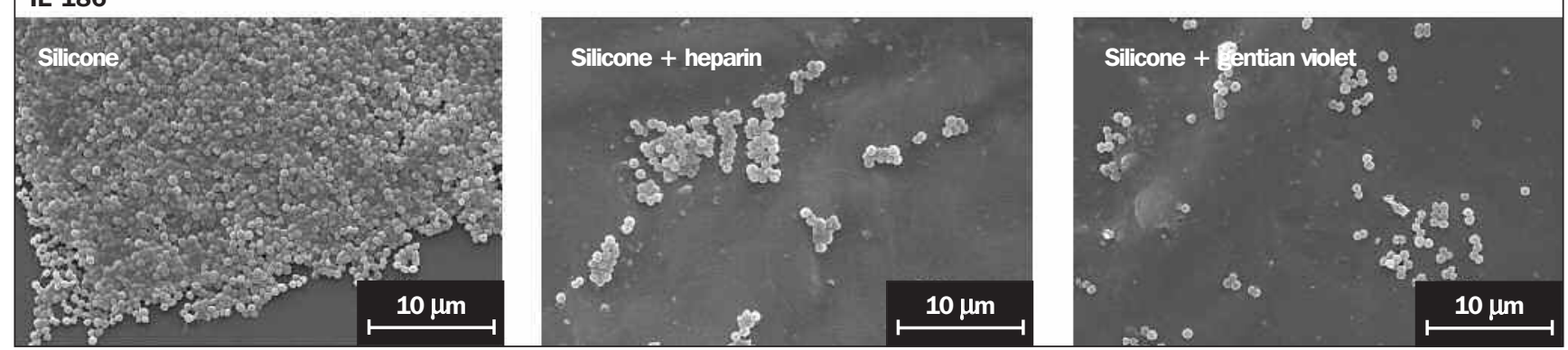
thus does not form biofilm. IE186 was a strain isolated from the blood of a patient with infective endocarditis. All strains were kindly provided by Dr. G. B. Pier, Channing Laboratory, Department of Medicine, Brigham and Women's Hospital, Harvard Medical School, Boston, USA.

\section{Media and growth conditions}

For the adhesion assays, cells were first grown for about $36 \mathrm{~h}$ on plates of tryptic soy agar (TSA), followed by 24-h incubation in $15 \mathrm{~mL}$ of tryptic soy broth (TSB) at $37^{\circ} \mathrm{C}$ in an orbital shaker at $120 \mathrm{rpm}$ (SI50; Stuart Scientific, Redhill, UK). The TSA and TSB media (Merck, Darmstadt, Germany) were prepared according to the manufacturer's instructions. A $50 \mu \mathrm{L}$ sample of each suspension were transferred to $30 \mathrm{~mL}$ fresh TSB broth and incubated for $18 \mathrm{~h}$ at $37^{\circ} \mathrm{C}$ and at $120 \mathrm{rpm}$. Cells were then centrifuged for $5 \mathrm{~min}$ at $9000 \mathrm{xg}$ at $4{ }^{\circ} \mathrm{C}$, and washed $(\mathrm{x} 2)$ with saline solution $(0.9 \% \mathrm{NaCl}[\mathrm{w} / \mathrm{v}$, Merck] in distilled water). The cell suspensions were adjusted to a final concentration of approximately $1 \times 10^{9}$ cells $/ \mathrm{mL}$, determined by absorbance at $640 \mathrm{~nm}$.

\section{Substrate preparation}

Acrylic and silicone were used as substrate in the adhesion assays, having been cut into $2 \times 2 \mathrm{~cm}$ squares. Prior to use, the coupons were washed several times with sterile distilled water and left to soak overnight. They were transferred to a new container with sterile distilled water and washed for 5 min with agitation, followed by 30 -min immersion in a $70 \%$

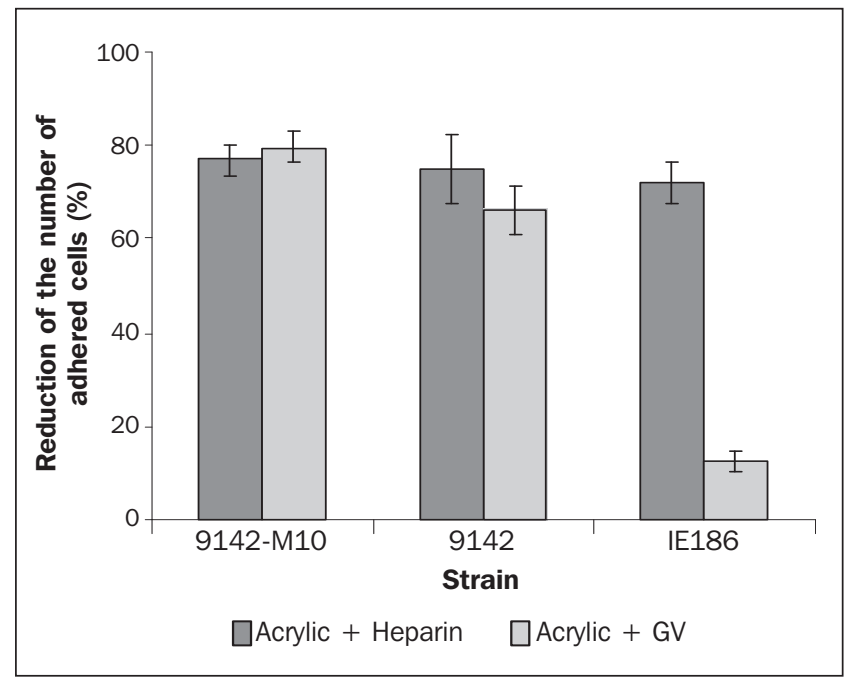

Fig. 3. Effect of heparin and gentian violet (GV) precontact on extent of $\mathrm{S}$. epidermidis adhesion to acrylic. a) Number of $\mathrm{S}$. epidermidis adhered cells to non-conditioned acrylic coupons (control) and to acrylic coupons precontacted with heparin or gentian violet (GV) for the three strains assayed (9142-M10, 9142 and IE186). Results represent means plus standard deviations (error bars). b) Representative scanning electro micrographs of the extent of adhesion of the three S. epidermidis strains studied to acrylic precontacted with heparin or gentian violet (original magnification $\times 3000$ ).
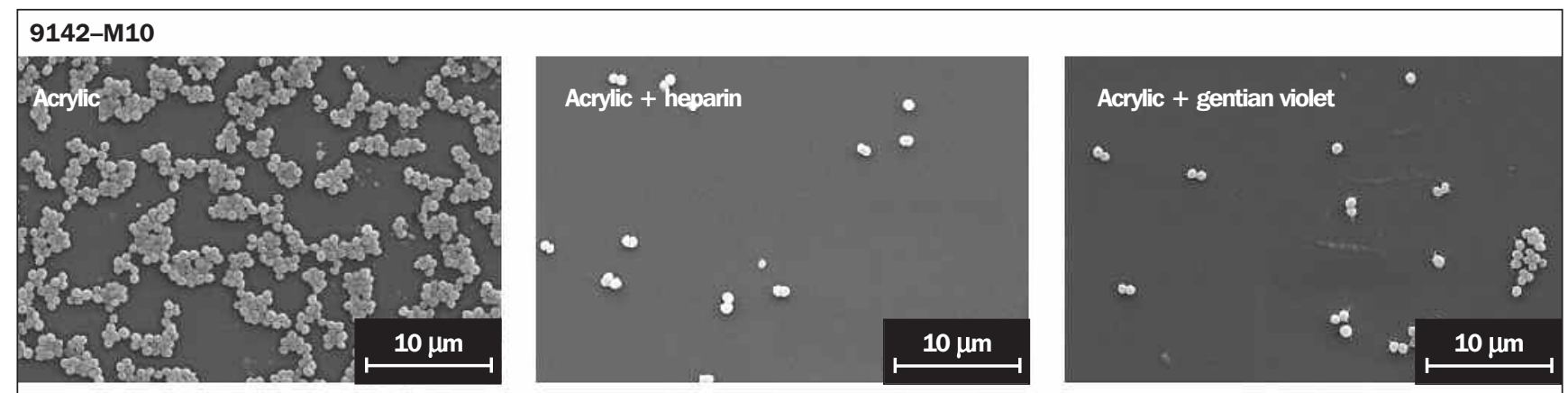

\section{2}
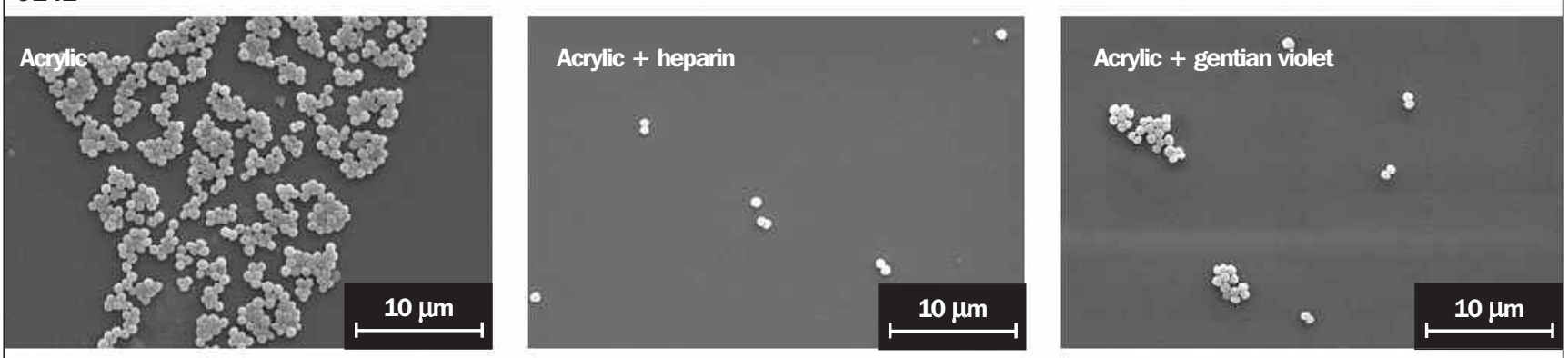

\section{IE 186}
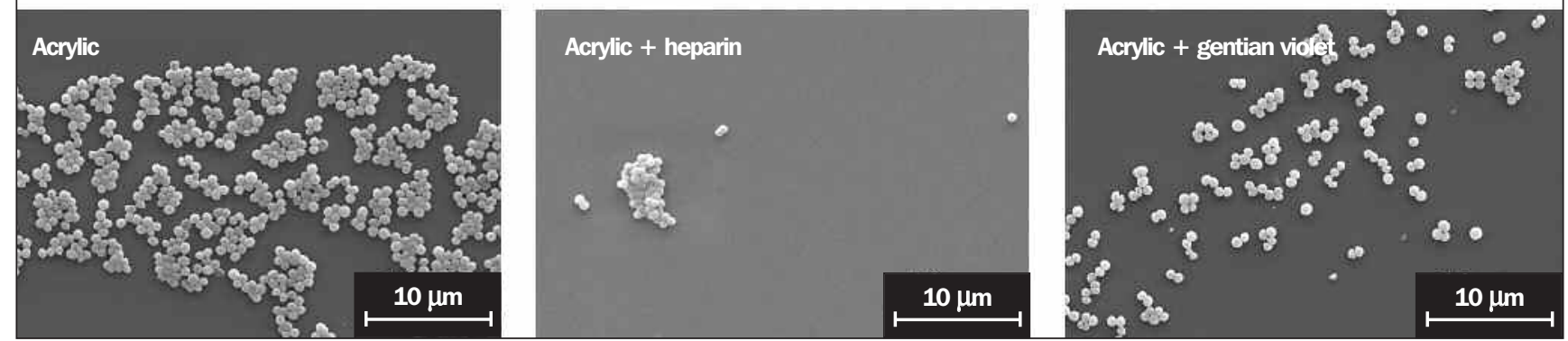
Table 1. Coefficient of variation (CV [\%]) of the effect of heparin precontact time on S. epidermidis adhesion to silicone.

\begin{tabular}{|c|c|c|c|c|}
\hline \multirow[b]{2}{*}{ Precontact time } & \multirow[b]{2}{*}{ Assay } & \multicolumn{3}{|c|}{ Intra-assay CVs } \\
\hline & & S. epidermidis 9142-M10 & S. epidermidis 9142 & S. epidermidis IE186 \\
\hline \multirow[t]{3}{*}{ Control } & 1 & 17.08 & 7.73 & 16.32 \\
\hline & 2 & 20.17 & 19.20 & 20.16 \\
\hline & 3 & 6.46 & 10.66 & 20.12 \\
\hline \multirow[t]{3}{*}{$10 \mathrm{~min}$} & 1 & 8.50 & 3.26 & 15.46 \\
\hline & 2 & 11.99 & 5.88 & 6.98 \\
\hline & 3 & 20.04 & 1.59 & 22.11 \\
\hline \multirow[t]{3}{*}{$30 \mathrm{~min}$} & 1 & 0.84 & 1.51 & 17.56 \\
\hline & 2 & 2.44 & 10.66 & 26.96 \\
\hline & 3 & 1.18 & 6.25 & 25.31 \\
\hline \multirow[t]{3}{*}{$2 \mathrm{~h}$} & 1 & 14.17 & 34.94 & 4.69 \\
\hline & 2 & 3.17 & 16.46 & 15.73 \\
\hline & 3 & 21.21 & 16.33 & 4.38 \\
\hline \multirow[t]{3}{*}{$24 \mathrm{~h}$} & 1 & 17.68 & 11.99 & 21.42 \\
\hline & 2 & 12.60 & 26.20 & 10.86 \\
\hline & 3 & 10.96 & 12.79 & 19.18 \\
\hline
\end{tabular}

Table 2. Coefficient of variation (CV [\%]) of the effect of heparin precontact time on S. epidermidis adhesion to silicone.

\begin{tabular}{lccc} 
& \multicolumn{4}{c}{ Inter-assay CVs } \\
\hline Precontact time & S. epidermidis $9142-M 10$ & S. epidermidis 9142 & S. epidermidis IE186 \\
\hline Control & 14.06 & 11.67 & 16.69 \\
$10 \mathrm{~min}$ & 13.55 & 8.19 & 21.52 \\
\hline $30 \mathrm{~min}$ & 2.37 & 18.65 & 21.50 \\
\hline $2 \mathrm{~h}$ & 12.94 & 29.38 & 17.98 \\
\hline 24 & 12.15 & 20.53 & 18.84
\end{tabular}

ethanol/sterile distilled water solution. Finally, the coupons were washed aseptically and individually with ultrapure sterile water and left to dry overnight at $60^{\circ} \mathrm{C}$.

\section{Heparin and GV precontact}

The silicone and acrylic coupons were immersed in nonfractioned and low-molecular-weight heparin $(5000 \mathrm{iu} / \mathrm{mL}$; Leo Pharmaceutical Products, Ballerup, Denmark) diluted (1 in 4 ) in distilled water, or in $1 \%$ gentian violet (Merck), and left to soak for $2 \mathrm{~h}$. To study the effect of heparin precontact time on bacterial adhesion, silicone coupons were also preincubated in heparin for $10 \mathrm{~min}, 30 \mathrm{~min}$ and $24 \mathrm{~h}$, and then removed aseptically and left to dry overnight at room temperature.

\section{Adhesion assays}

Adhesion assays were performed as previously described.$^{20}$ Briefly, the preconditioned coupons were placed in six-well tissue culture plates (Sarstedt, Newton, NC, USA) containing $4 \mathrm{~mL}$ of a suspension of $1 \times 10^{9}$ cells $/ \mathrm{mL}$ in $0.9 \% \mathrm{NaCl}$. Adhesion was allowed to occur for $2 \mathrm{~h}$ at $37^{\circ} \mathrm{C}$ in a shaker rotating at $120 \mathrm{rpm}$. Each coupon was then removed and washed by immersion to remove loosely attached cells. This procedure involved gentle transfer to a $100 \mathrm{~mL}$ glass beaker containing $50 \mathrm{~mL}$ distilled water for about $10 \mathrm{sec}$, followed by transfer to a second $100 \mathrm{~mL}$ glass beaker containing $50 \mathrm{~mL}$ distilled water for $10 \mathrm{sec}$, and then to a third for $10 \mathrm{sec}^{21}$ The coupons were then left to dry at $37^{\circ} \mathrm{C}$ for about $1 \mathrm{~h}$. All experiments were performed in triplicate and repeated in three independent assays.

\section{Total cell counts of adherent bacteria}

The dried coupons were stained with a 4-6-diamidino-2phenylindole (DAPI; Sigma, USA) solution (0.1 g/L) for $30 \mathrm{~min}$. Each coupon was rinsed with distilled water and left to air-dry in the dark for $30 \mathrm{~min}$. Adherent cells were visualised under an epifluorescence microscope (filter sensitive to DAPI fluorescence) coupled with a video camera. Enumeration of adherent cells was performed using automated enumeration software (SigmaScan Pro 5) and results were presented as number of adhered cells $/ \mathrm{cm}^{2}$.

\section{Scanning electron microscopy}

The coupons were dehydrated by $15-\mathrm{min}$ immersion in increasing ethanol concentrations $(10,25,40,50,60,70,80,90$ and $100 \%[\mathrm{v} / \mathrm{v}])$, and then placed in a sealed desiccator. Samples were mounted on aluminium stubs with carbon tape, sputter coated with gold and observed with a Leica Cambridge S-360 scanning electron microscope (Leo, Cambridge, UK). Three fields were used for image analysis. 


\section{Statistical analysis}

Results obtained were analysed using SPSS software (Statistical Package for the Social Sciences Inc., Chicago) and all tests were performed with a confidence level of $95 \%$. The Kolmogorov-Smirnov test was used to confirm a normal distribution of results. The effect of preconditioning time with heparin was analysed using a two-way ANOVA (repeated measures) with Wilks' Lambda test. Results of the adhesion assays were compared using one-way ANOVA by applying the Tukey multiple comparisons test. The independent samples $t$-test was also used to compare the effect of the same conditioning substance on acrylic and on silicone.

\section{Results}

\section{Effect of heparin precontact time}

The first approach aimed to assess the extent of adhesion of S. epidermidis strains to silicone coupons preconditioned with heparin for $10 \mathrm{~min}, 30 \mathrm{~min}, 2 \mathrm{~h}$ and $24 \mathrm{~h}$. A statistically significant effect on the extent of adhesion of all S. epidermidis strains to heparin (Wilks' Lambda $=0.001$, $P<0.001$ for strain 9142-M10; Wilks' Lambda $=0.023$, $P<0.001$ for strain 9142 and Wilks' Lambda $=0.025, P<0.007$ for strain IE186). Figure 1 shows a significant difference $(P<0.05)$ between the number of cells adherent to the silicone control coupons and the extent of bacterial adhesion to all heparin precontacted coupons over several preconditioning times, and for all strains. Least adhesion was observed after $2 \mathrm{~h}$ of heparin precontact for all three strains assayed. Adhesion of strains 9142 and IE186 showed small variations with all the precontact periods tested, while strain 9142-M10 displaying greater variability of adhesion with the various heparin precontact times.

\section{Effect of heparin and gentian violet precontact}

Subsequent assays were performed with 2-h precontact for both conditioning substances.

In the case of silicone, a significant decrease $(P<0.005)$ in bacterial adhesion following the use of heparin or GV was observed (Fig. 2) for all strains studied $(P<0.001)$. No statistical differences $(P>0.05)$ were found between the extent of adhesion following precontact with either heparin or GV for each of the strains tested; however, on coupons precontacted with GV, adherence of strain 9142-M10 was significantly lower $\left(4.48 \times 10^{6} \pm 9.44 \times 10^{5} \mathrm{cells} / \mathrm{cm}^{2}\right)$ comparing to strains $9142\left(1.04 \times 10^{7} \pm 1.84 \times 10^{6}\right.$ cells $\left./ \mathrm{cm}^{2} ; P<0.001\right)$ and IE186 $\left(1.39 \times 10^{7} \pm 3.07 \times 10^{6} \mathrm{cells} / \mathrm{cm}^{2} ; P<0.001\right)$. In the case of silicone precontacted with heparin, a statistical difference $(\mathrm{P}<0.001)$ was observed between strain 9142-M10 (6.16x10 $\pm 7.98 \times 10^{5}$ cells $\left./ \mathrm{cm}^{2}\right)$ and strain IE186 $\left(1.21 \times 107 \pm 2.17 \times 10^{6}\right.$ cells $\left./ \mathrm{cm}^{2}\right)$, with strain 9142 presenting an intermediate level of reduction in the number of adherent cells $\left(8.51 \times 10^{6} \pm\right.$ $2.50 \times 10^{6} \mathrm{cells} / \mathrm{cm}^{2}, P=0.047$ ).

In the case of acrylic conditioning (Fig. 3), both precontacted surfaces showed significantly lower levels of adherent cells $(P=0.001)$ for all strains. With strain 9142-M10, the number of adherent cells to acrylic was almost independent of the conditioning substance used $(P=0.984)$. With strain 9142, the number of attached cells was less pronounced on acrylic precontacted with heparin $\left(3.07 \times 10^{6}\right.$ $\pm 1.07 \times 10^{6}$ cells $\left./ \mathrm{cm}^{2}\right)$ than with GV $\left(5.04 \times 10^{6} \pm 5.26 \times 10^{5}\right.$ cells $\left./ \mathrm{cm}^{2}\right)$. In the case of IE186, heparin showed significantly $(P<0.001)$ higher efficacy in acrylic conditioning, with only $4.36 \times 106$ cells adherent against $1.35 \times 10^{7}$ cells $/ \mathrm{cm}^{2}$ when conditioned with GV. Therefore, on acrylic substances, heparin reconditioning is slightly more efficient in reducing S. epidermidis adhesion than is GV.

In the acrylic surface control and the pre-incubated GV sample groups, the extent of adhesion of strain IE186 was significantly higher than the adhesion of strains 9142-M10 and $9142(P<0.001)$. On the other hand, following heparin pre-incubation, $S$. epidermidis 9142-M10 showed greater adherence $(P<0.001)$ than strains IE186 and 9142 . Therefore, S. epidermidis 9142 was most affected by the preconditioning of acrylic with heparin and GV.

The number of adherent cells of all three S. epidermidis strains was markedly lower $(P<0.001)$ on acrylic than on silicone when the surfaces were not preconditioned. Moreover, when surfaces were precontacted with heparin, cells showed greater adherence to silicone than to acrylic, especially strains 9142 and IE186 $(P<0.001)$. A similar difference was observed for strain 9142-M10 $(P=0.009)$ and strain $9142(P<0.001)$ adherent to material coated with GV.

\section{Discussion}

One of the main sources of contamination of indwelling medical devices (e.g., catheters) is the skin insertion site. From this point, microorganisms migrate towards the intracutaneous tract on the exterior surface of the catheter, subsequently colonising it and causing sepsis. ${ }^{2}$ Therefore, heparin or GV preconditioning of the inner and outer surfaces of such devices can act to preventive the development of infection.

The results of the present study agree with those of previous work on the use of such substances to prevent bacterial proliferation. ${ }^{7,8,14,16}$ Rose et al. ${ }^{5}$ also confirmed the ability of heparin preconditioning to reduce bacterial adhesion to cationic MPC co-polymers. Another study ${ }^{22}$ of S. epidermidis adhesion to intraocular lenses (IOLs) demonstrated that heparin treatment significantly reduced the extent of adhesion of these bacteria to regular polymethyl methacrylate (PMMA) IOLs, compared to antibiotic treatment. Similar results were obtained by Portolés et al. ${ }^{9}$ when performing adhesion studies of $S$. epidermidis to PMMA IOLs in the presence of heparin in solution.

These studies, together with the results of the present work, indicate that the preconditioning of indwelling medical devices with heparin may constitute a valid alternative to antibiotics, which are inefficient in reducing adhesion and biofilm formation on such surfaces. However, the mechanism by which heparin inhibits bacterial adhesion remains unclear, although it is not related to its action as an anticoagulant. ${ }^{23}$ Heparin is composed of long hydrophilic chains and has a negative charge, and these factors are likely to play a role in inhibiting adherence. ${ }^{24}$ S. epidermidis also has a negative charge, which may lead to the bacterium being repelled from the heparin preconditioned surface.

Saji et al. ${ }^{16}$ demonstrated a significant in vitro bactericidal effect for GV on methicillin-resistant S. aureus (MRSA) isolated from clinical specimens, as well as in the treatment of decubitus ulcers infected with MRSA. The present results also point to considerably efficacy against CNS such as 
Table 3. Coefficient of variation (CV [\%]) of the effect of heparin and gentian violet (GV) precontact time on S. epidermidis adhesion to silicone and acrylic

\begin{tabular}{|c|c|c|c|c|}
\hline \multirow[b]{2}{*}{ Material } & \multirow[b]{2}{*}{ Assay } & \multicolumn{3}{|c|}{ Intra-assay CVs } \\
\hline & & S. epidermidis 9142-M10 & S. epidermidis 9142 & S. epidermidis IE186 \\
\hline \multirow[t]{3}{*}{ Silicone } & 1 & 17.08 & 7.73 & 16.32 \\
\hline & 2 & 13.90 & 19.20 & 20.16 \\
\hline & 3 & 11.75 & 6.81 & 9.55 \\
\hline \multirow[t]{3}{*}{ Silicone + heparin } & 1 & 14.17 & 24.94 & 4.69 \\
\hline & 2 & 3.17 & 16.46 & 25.73 \\
\hline & 3 & 21.21 & 16.33 & 4.38 \\
\hline \multirow[t]{3}{*}{ Silicone + GV } & 1 & 20.52 & 7.55 & 21.54 \\
\hline & 2 & 23.71 & 22.91 & 26.53 \\
\hline & 3 & 10.97 & 10.84 & 21.86 \\
\hline \multirow[t]{3}{*}{ Acrylic } & 1 & 9.46 & 8.84 & 0.72 \\
\hline & 2 & 10.09 & 12.49 & 0.88 \\
\hline & 3 & 11.72 & 15.69 & 0.86 \\
\hline \multirow[t]{3}{*}{ Acrylic + heparin } & 1 & 20.72 & 28.85 & 16.00 \\
\hline & 2 & 16.07 & 23.72 & 13.36 \\
\hline & 3 & 11.27 & 17.98 & 5.20 \\
\hline \multirow[t]{3}{*}{ Acrylic + GV } & 1 & 5.13 & 15.76 & 7.29 \\
\hline & 2 & 21.45 & 8.63 & 0.79 \\
\hline & 3 & 10.60 & 3.88 & 3.55 \\
\hline
\end{tabular}

Table 4. Coefficient of variation (CV [\%]) on the effect of heparin and gentian violet (GV) precontact time on $\mathrm{S}$. epidermidis adhesion to silicone and acrylic.

\begin{tabular}{lccc}
\multicolumn{5}{c}{ Inter-assay CVs } \\
\hline Material & S. epidermidis 9142-M10 & S. epidermidis 9142 & S. epidermidis IE186 \\
\hline Silicone & 12.72 & 10.91 & 14.15 \\
\hline Silicone + heparin & 12.94 & 19.38 & 17.98 \\
\hline Silicone + GV & 21.06 & 17.66 & 21.98 \\
\hline Acrylic & 9.24 & 11.21 & 1.17 \\
Acrylic + heparin & 14.91 & 14.95 & 15.02 \\
\hline Acrylic + GV & 14.11 & 10.44 & 6.13 \\
\end{tabular}

S. epidermidis. Therefore, GV seems to possess antimicrobial activity that can be used against an important group of pathogens normally associated with nosocomial infections.

In aqueous solutions, GV dissociates into positive and negative ions that pass through the cell wall of Grampositive bacteria such as $S$. epidermidis. The positive ions then interact with negatively charged cell components such as peptidoglycan and DNA. ${ }^{25}$ As GV is a mutagen and mitotic poison, cell growth is inhibited. This mode of action, as an antimicrobial agent, possibly explains the efficacy of GV against bacteria and yeasts, while showing only mild to moderate effects on mammalian cells. Chaiban et al. ${ }^{18}$ evaluated the cytotoxicity of an antiseptic combination of $\mathrm{GV}$ and chlorhexidine (Gendine) and reported no cytotoxicity against L929 mouse fibroblast cells.

In the present study, some differences were observed between strain 9142-M10, which is an isogenic mutant of the biofilm-negative strain 9142, and strains 9142 and IE186, which have been defined as biofilm producers. ${ }^{20,26}$ Cerca et al..$^{20}$ showed that adhesion and biofilm formation are two features associated with the pathogenicity of infections associated with medical devices, and that high levels of initial adherence do not necessarily lead to strong biofilm formation. This can be due to the fact that biofilm formation depends mostly on cell adhesion phenomena. On the other hand, initial adhesion also depends on several other bacterial cell surface factors. Thus, it is important to note that biofilm formation is not solely dependent on the extent of initial adherence of bacteria to the substrate, but that adhesion is a strain-dependent and not a species-dependent factor.

Nosocomial infections due to CNS such as S. epidermidis may be caused by factors including the use of indwelling medical devices, previous antibiotics administration and 
infection control practices adopted by medical personnel. ${ }^{27}$ The results presented in this work have potential clinical significance and show that both heparin and GV are effective in reducing bacterial adhesion. Pretreatment of indwelling medical devices with such substances therefore can act as an infection control measure and may constitute a successful means to reduce the incidence of nosocomial infection.

The authors acknowledge the financial support of the Portuguese Science Foundation (FCT) through project POCTI/ESP/42688/2001. C. Sousa and P. Teixeira acknowledge the financial support of FCT through grants SFRH/BD/19265/2004 and SFRH/BPD/26803/2006, respectively.

\section{References}

1 Kogan G, Sadovskaya I, Chaignon P, Chokr A, Jabbouri S. Biofilms of clinical strains of Staphylococcus that do not contain polysaccharide intercellular adhesin. FEMS Microbiol Lett 2006; 255: 11-6.

2 Worthington T, Lambert PA, Elliott TSJ. Is hospital-acquired intravascular catheter related sepsis associated with outbreak strains of coagulase-negative staphylococci? J Hosp Infect 2000; 46: $130-4$.

3 Ziebuhr W, Hennig S, Eckart M, Kränzler H, Batzilla C, Kozitskaya S. Nosocomial infections by Staphylococcus epidermidis: how a commensal bacterium turns into a pathogen. Int J Antimicrob Agents 2006; 28 (Suppl 1): S14-20.

4 Barrett SP. Control of the spread of multi-resistant gram-positive organisms. Curr Anaesth Crit Care 1999; 10: 27-31.

5 Rose SF, Okere S, Hanlon GW, Lloyd AW, Lewis AL. Bacterial adhesion to phosphorylcholine-based polymers with varying cationic charge and the effect of heparin pre-adsorption. J Mater Sci Mater Med 2005; 16: 1003-15.

6 Edmiston C, Schmitt A, Krepel C, Seabrook G. Impact of triclosan-impregnated suture on in vitro adherence of nosocomial surgical pathogens (Abstract). Am J Infect Control 2004; 32: E108.

7 Tenke P, Riedl CR, Jones GL, Williams GJ, Stickler D, Nagy E. Bacterial biofilm formation on urologic devices and heparin coating as preventive strategy. Int J Antimicrob Agents 2004; 23 (Suppl 1): S67-74.

8 Arciola CR, Caramazza R, Pizzoferrato A. In vitro adhesion of Staphylococcus epidermidis on heparin-surface-modified intraocular lenses. J Cataract Refract Surg 1994; 20: 158-61.

9 Portolés M, Refojo MF, Leong FL. Reduced bacterial adhesion to heparin-surface-modified intraocular lenses. J Cataract Refract Surg 1993; 19: 755-9.

10 Nelson SR, de Souza NM, Allison DJ. Endovascular stents and stent-grafts: is heparin coating desirable? Cardiovasc Intervent Radiol 2000; 23: 252-5.

11 Denizli A. Heparin-immobilized poly(2hydroxyethylmethacrylate)-based microspheres. J Appl Polymer Sci 1999; 74: 655-62.

12 Randolph AG, Cook DJ, Gonzales CA, Andrew M. Benefit of heparin in peripheral venous and arterial catheters: systematic review and meta-analysis of randomised controlled trials. BMJ 1998; 316: 969-75.

$13 \mathrm{Fu} \mathrm{J}$, Ji J, Yuan W, Shen J. Construction of anti-adhesive and antibacterial multilayer films via layer-by-layer assembly of heparin and chitosan. Biomaterials 2005; 26: 6684-92.

14 Nomura S, Lundberg F, Stollenwerk M, Nakamura K, Ljungh A. Adhesion of staphylococci to polymers with and without immobilized heparin in cerebrospinal fluid. J Biomed Mater Res 1997; 38: 35-42.

15 Thompson HC Jr, Rushing LG, Gehring T, Lochmann R. Persistence of gentian violet and leucogentian violet in channel catfish (Ictalurus punctatus) muscle after waterborne exposure. J Chromatogr B Biomed Sci Appl 1999; 723: 287-91.

16 Saji M, Taguchi S, Uchiyama K, Osono E, Hayama N, Ohkuni H. Efficacy of gentian violet in the eradication of methicillinresistant Staphylococcus aureus from skin lesions. J Hosp Infect 1995; 31: 225-8.

17 Albertini JG. Surgical pearl: gentian violet-dyed sutures improve intraoperative visualization. J Am Acad Dermatol 2001; 45: 453-5.

18 Chaiban G, Hanna H, Dvorak T, Raad I. A rapid method of impregnating endotracheal tubes and urinary catheters with Gendine: a novel antiseptic agent. J Antimicrob Chemother 2005; 55: 51-6.

19 Mack D, Haeder M, Siemssen N, Laufs R. Association of biofilm production of coagulase-negative staphylococci with expression of a specific polysaccharide intercellular adhesin. J Infect Dis 1996; 174: 881-4.

20 Cerca N, Pier GB, Vilanova M, Oliveira R, Azeredo J. Quantitative analysis of adhesion and biofilm formation on hydrophilic and hydrophobic surfaces of clinical isolates of Staphylococcus epidermidis. Res Microbiol 2005; 156: 506-14.

21 Cerca N, Pier GB, Oliveira DR, Azeredo J. Comparative evaluation of coagulase-negative staphylococci (CoNS) adherence to acrylic by a static method and a parallel-plate flow dynamic method. Res Microbiol 2004; 155: 755-60.

22 Abu El-Asrar AM, Shibl AM, Tabbara KF, Al-Kharashi SA. Heparin and heparin-surface-modification reduce Staphylococcus epidermidis adhesion to intraocular lenses. Int Ophthalmol 1997; 21: 71-4.

23 Hanno PM, Fritz RW, Mulholland SG, Wein AJ. Heparin - an examination of its antibacterial adsorption properties. Eur Urol 1981; 7: 359-62.

24 Pringle JH, Fletcher M. Influence of substratum hydration and absorbed macromolecules on bacterial attachment to surfaces. Appl Environ Microbiol 1986; 51: 1321-5.

25 Wishart DS, Knox C, Guo AC et al. DrugBank: a comprehensive resource for in silico drug discovery and exploration. Nucleic Acids Res 2006; 34 (database issue): D668-72.

26 Mack D, Nedelmann M, Krokotsch A, Schwarkkopf A, Heesemann J, Laufs R. Characterization of transposon mutants of biofilm-producing Staphylococcus epidermidis impaired in the accumulative phase of biofilm production: genetic identification of a hexosamine-containing polysaccharide intercellular adhesin. Infect Immun 1994; 62: 3244-53.

27 Koksal F, Yasar H, Samasti M. Antibiotic resistance patterns of coagulase negative staphylococcus strains isolated from blood cultures of septicemic patients in Turkey. Microbiol Res 2007, April 30 (Epub ahead of print). 